Fixed Point Theory, 21(2020), No. 2, 767-790

DOI: $10.24193 /$ fpt-ro.2020.2.55

http://www.math.ubbcluj.ro/ nodeacj/sfptcj.html

\title{
ON THE ARONSZAJN PROPERTY FOR FRACTIONAL NEUTRAL EVOLUTION EQUATIONS WITH INFINITE DELAY ON HALF-LINE
}

\author{
NGUYEN NGOC TRONG*, LE XUAN TRUONG** AND NGUYEN THANH TUNG*** \\ *Department of Primary Education, HCMC University of Education \\ E-mail: trongnn@hcmue.edu.vn \\ ${ }^{* *}$ Division of Computational Mathematics and Engineering, Institute for Computational Science \\ Ton Duc Thang University, Ho Chi Minh City, Vietnam \\ Faculty of Mathematics and Statistics, Ton Duc Thang University, Ho Chi Minh City \\ E-mail: lexuantruong@tdtu.edu.vn (Corresponding author) \\ *** Department of Mathematics, HCMC University of Education \\ E-mail: thanhtungnt86@gmail.com
}

\begin{abstract}
We establish an $R_{\delta}$ structure theorem for the fixed point set of the Krasnosel'skii type operator on Fréchet space. Applying this result, a topological structure for the set of all mild solutions of fractional neutral evolution equations with infinite delay on half-line is investigated. We show that the solution set is an $R_{\delta}$-set.
\end{abstract}

Key Words and Phrases: Topology structure, solution set, fractional differential equation, Krasnosel'skii type operator.

2010 Mathematics Subject Classification: 34A12, 34G20, 34A08, 47H10.

Acknowledgement. We would like to thank the referees for their valuable comments.

\section{REFERENCES}

[1] J. Andres, G. Gabor, L. Górniewicz, Boundary value problems on infinite intervals, Trans. Amer. Math. Soc., 351(1999), 4861-4903.

[2] J. Andres, L. Górniewicz, Topology Fixed Point Priciples for Boundary Value Problems, Topol. Fixed Point Theory Appl, Kluwer, Dordrecht, 2003.

[3] P.N. Aronszajn, Le correspondant topologique de l'unicité dans la theorie des equations différentielles, Annals of Mathematics, 43(1942), 730-78.

[4] E.G. Bajlekova, Fractional Evolution Equations in Banach Spaces, Ph.D. Thesis, Eindhoven University of Technology, 2001.

[5] D. Baleanu, O.G. Mustafa, On the global existence of solutions to a class of fractional differential equations, Comput. Math. Appl., 59(5)(2010), 835-1841.

[6] D. Baleanu, O.G. Mustafa, R.P. Agarwal, An existence Result for a superlinear fractional differential equation, Appl. Math. Lett., 23(9)(2010), 1129-1132.

[7] J. Banas, K. Goebel, Measure of Noncompactness in Banach spaces, Lecture Notes in Pure and Applied Math, 60, Dekker, New York, 1990. 
[8] K. Borsuk, Theory of Retracts, vol. 44, Monografie Matematyczne PWN, Warsaw, 1967.

[9] F.E. Browder, C.P. Gupta, Topological degree and nonlinear mappings of analytic type in Banach space, J. Math. Anal. Appl, 26(2010), 390-402.

[10] D. Bugajewska, On the structure of solution sets of differential equations in Banach spaces, Math. Slovaca, 50(2000), 463-471.

[11] M. Cichón, I. Kubiaczyk, Some remarks on the structure of the solution set for differential inclusions in Banach spaces, J. Math. Anal. Appl., 233(1990), 597-606.

[12] F.S. De Blasi, J. Myjak, On the solution sets for differential inclusion, Bull. Pol. Acad. Sci. Math., 12(1985), 17-23.

[13] S.D. Eidelman, A.N. Kochubei, Cauchy problem for fractional diffusion equations, J. Differential Equations, 199(2004), 211-255.

[14] M.M. El-Borai, Semigroups and some nonlinear fractional differential equations, Applied Math. Comput., 149(2004), 823-831.

[15] M.M. El-Borai, Some probability densities and fundamental solutions of fractional evolution equations, Chaos Solitons \& Fractals, 149(2004), 823-831.

[16] X. Fu, K. Ezzinbi, Existence of solutions for neutral differential evolution equations with nonlocal conditions, Nonlinear Anal., 54(2003), 215-227.

[17] G. Gabor, On the acyclicity of fixed point sets of multivalued maps, Topological Methods in Nonlinear Analysis, 14(1999), 327-343.

[18] L. Górniewicz, Topological structure of solution sets: current results, Archivum Mathematicum, 36(2000), 343-382.

[19] L. Górniewicz, Solving equations by topological methods, Opuscula Mathematica, 25(2005), 195225.

[20] H.P. Heinz, On the behaviour of measure of noncompactness with respect to differentiation and integration of vector-valued functions, Nonlinear Anal., 7(1983), 1351-1371.

[21] L.H. Hoa, K. Schmitt, Fixed point theorems of Krasnosel'skii type in locally convex space and applications to integral equation, Results in Mathematics, 25(1994), 291-313.

[22] L.H. Hoa, K. Schmitt, Periodic solutions of functional-differential equations of retarded and neutral types in Banach spaces, Boundary Value Problems for Functional-Differential Equations, World Scientific, New Jersey, (1995), 177-185.

[23] O.K. Jardat, A. Al-Omari, S. Momani, Existence of the mild solution for fractional semilinear initial value problems, Nonlinear Anal., 69(9)(2008), 3153-3159.

[24] S. Ji, G. Li, M. Wang, Controllability of impulsive differential systems with nonlocal conditions, Appl. Math. Comput., 217(2011), 6981-6989.

[25] M.A. Krasnoselskii, Two remarks on the method of successive approximations, Uspekhi Mat. Nauk., 10(1955), 123-127.

[26] W. Kryszewski, Topological structure of solution sets of differential inclusions: the constrained case, Abstract and Applied Analysis, (2003), 325-351.

[27] Z. Kubacek, On the structure of fixed point sets of some compact maps in the Fréchet space, Mathematica Bohemica, 118(1993), 343-358

[28] F. Mainardi, P. Paradisi, R. Gorenflo, Probability distributions generated by fractional diffusion equations, in: J. Kertesz, I. Kondor (Eds.), Econophysics: An Emerging Science, Kluwer, Dordrecht, 2000.

[29] J.J. Nieto, Aronszajn's theorem for some nonlinear Dirichlet problems with unbounded nonlinearities, Proc. Edinburgh Mathematical Society, 31(1988), 345-351.

[30] S. Park, Generalizations of the Krasnosels'kii fixed point theorem, Nonlinear Anal., 67(2007), 3401-3410.

[31] A. Pazy, Semigroups of Linear Operators and Applications to Partial Differential Equations, Springer, New York, 1983.

[32] J.P.C. Santos, M.M. Arjunan, C. Cuevas, Existence results for fractional neutral integrodifferential equations with state dependent delay, Comput. Math. Appl., 62(2011), 1275-1283.

[33] J.P.C. Santos, V. Vijayakumar, R. Murugesu, Existence of mild solutions for nonlocal Cauchy problem for fractional neutral integro-differential equation with unbounded delay, Commun. Math. Anal., 14(2013), 59-71. 
[34] S. Szufla, Sets of fixed points nonlinear mappings in function spaces, Funkcial. Ekvac., 22(1979), 121-126.

[35] C.C. Travis, G.F. Webb, Cosine families and abstract nonlinear second order differential equations, Acta Math. Sci. Hung., 32(1978), 75-96.

[36] J.R. Wang, Z. Fan, Y. Zhou, Nonlocal controllability of semilinear dynamic systems with fractional derivative in Banach spaces, J. Optim. Theory Appl., 154(2012), 292-302.

[37] J. Wang, Y. Zhou, M. Fekan, Abstract Cauchy problem for fractional differential equations, Nonlinear Dynam., 74(2013), 685-700.

[38] B. Yan, Boundary value problems on the half-line with impulses and infinite delay, J. Math. Anal. Appl., 259(2001), 94-114.

[39] X. Zheng, X. Yang, The structure of weak Pareto solution sets in piecewise linear multiobjective optimization in normed spaces, Science in China, Series A: Mathematics, 51(2008), 1243-1256.

[40] Y. Zhou, F. Jiao, Existence of mild solutions for fractional neutral evolution equations, Comput. Math. Appl., 59(2010), 1063-1077.

Received: March 26, 2018; Accepted: November 14, 2018. 
